\title{
Rescue responses during a full moon and Friday 13th
}

\author{
Ian Greatbatch and Robert J. Koester \\ School of Earth and Environmental Sciences, University of Portsmouth, Portsmouth, UK, and \\ Andrea L. Kleinsmith \\ University of Maryland - Baltimore County, Baltimore, Maryland, USA
}

Keywords Superstition, Data, Evidence, Rescue

The authors would like to thank the London Fire Brigade, Mountain Rescue England and Wales, all of the data contributors and administrators of the International Search \& Rescue Incident Database, the Royal National Lifeboat Institution and the Association of Lowland Search and Rescue for making data available for research.

\begin{abstract}
Purpose - It is a well held belief that the full moon period and the date Friday 13th has an impact on the number of emergency call outs for emergency services. The purpose of this paper is to critically explore that belief. It also examines the versatility and richness of response records, and demonstrates the effectiveness of combining data sets.
\end{abstract}

Design/methodology/approach - The work takes four varied data sets, from four rescue agencies along with the International Search and Rescue Database and compared the average number of calls on a full moon night, non-full moon and full moon period (the full moon night, the day before and day after). The average number of incidents on Friday 13th was also investigated. It uses a statistical approach to test the difference between "normal" dates and those dates traditionally believed to be busier.

Findings - Although there were differences between Friday 13th, full moon nights, full moon periods and "normal" days, the differences were in general extremely small, not significantly significant and in most cases actually dropped during the supposedly unlucky period. The exception to this is a very small increase in the average number of responses during full moons for most data sets, although this was not statistically significant. This paper concludes that there is no evidence in the data for any impact of the full moon upon rescue teams' activities.

Research limitations/implications - This research deals with a small set of responses, from the UK only, and addresses an issue that is clearly not the most pressing. However, it does demonstrate evidencedbased management in practice, in that resources have incorrectly been assigned in the past to these dates.

Practical implications - This work shows that preconceptions exist within the emergency services and that, without evidence-led management, resources can be allocated on hearsay. This shows that widely available software and techniques can be applied to organisational data and used to make management decisions more appropriate.

Social implications - Rescue organisations are almost exclusively charity or public sector organisations, meaning that their budgets are sourced from donations or the tax-payer. Putting to bed misconceptions over resources for certain dates will ultimately benefit society in those terms. 
Originality/value - There has been very little work on this phenomenon, although some works on A\&E department admissions have taken place. This is the only work to date to combine data in this way for this purpose.

\section{Introduction}

A common belief found within emergency services is that the number and frequency of incidents increases during the full moon period. There have been high profile cases of police departments increasing staff over those periods in both the UK and USA, in response to perceived rises in events. Although equally commonly regarded as unlikely, it is not uncommon to hear public safety officials including search and rescue (SAR) workers refer to full moon periods, or Friday the 13th as a trouble spot.

For example, in Brighton, UK in 2007, after an increase in incidents over the full moon, a police inspector was quoted as saying "From my experience, over 19 years of being a police officer, undoubtedly on full moons, we do seem to get people with, sort of, stranger behaviour - more fractious, argumentative" (BBC, 2007).

There have been numerous studies into both the full moon and Friday the 13th phenomena. Wellconstructed studies have largely debunked the superstition. However, only two studies have looked at public safety (Bickis et al., 1995; Frey et al., 1979) and this is the first study to our knowledge to address SAR.

This paper will review existing literature concerning the phenomena, and where possible determine best practice for investigating it. It will then seek to use new and rich data specific to the $\mathrm{SAR} /$ emergency services sectors, investigate if any relationship exists between phase of moon/Friday the 13th and the likelihood of a rescue service being initiated. It is hoped that this will inform emergency services and voluntary rescue organisations in terms of staffing, strategic and tactical planning and in informing and reassuring the public.

\section{Literature review}

The superstitious belief in Friday the 13th and the full moon's influence on behaviour remains prevalent in contemporary society. The belief in significant times of the year or specific dates can be traced back to early man's relationship with the environment, seeing patterns in nature and agriculture related to phases of the moon and, in turn, imbuing the lunar cycle with supernatural qualities, in the form of gods or goddesses. The origins of these beliefs can be traced back to ancient times as described in several studies (Lo et al., 2012; Schuld et al., 2011).

Friday the 13th is considered unlucky as a concatenation of two unlucky factors: the day Friday, which is traditionally held to be the day Christ was crucified, and the number 13 , considered unlucky in a number of cultures, but again having a Christian origin, in 13 being the number associated with Christ and the apostles at the last supper, although according to Lorie (1992), the Romans considered 13 unlucky prior to that. There is also a suggestion by Gooch (2006) in the hybrid-origin theory of human development that the number 13 represented a repressed form of proto-religion, with it being considered anathema as other religions took precedence.

Norse mythology also contains reference to Friday and 13, with the banished goddess Frigga (after whom Friday is so named) meeting with 12 conspirators of witches and demons (making 13) to plan revenge and havoc for the following week. Norse mythology also counts the mischievous and 
treacherous god Loki as the 13th god to arrive at dinner (Fidrmuc and Tena, 2014), bringing bad luck to the party.

We can therefore see that across a number of cultures, and particularly in modern culture, fuelled by horror films, the fear of Friday the 13th (called Triskaidekaphobia or friggatriskaidekaphobia) and of full moons (selenophobia) is well established.

A small number of empirical studies have looked at the link between Friday the 13th and various outputs. Krajewska-Kulak et al. (2011) reported that 70 per cent of the population from the Podlaskie province (Poland) believe (respected) that Friday the 13th is a day for bad luck. Scanlon et al. (1993) concluded that the risk of a hospital admission as a result of a vehicle accident on Friday the 13th increased by 52 per cent. Nayha (2002) determined that the Scanlon et al. (1993) study size was too small for meaningful analysis and repeated the study with six years' worth of data from Finland. No increased risk was found for men but for women a 38 per cent increase was found (one-death per $5 \mathrm{~m}$ person days). This increase was attributed to increased anxiety. Radun and Summala (2004) used 14 years of Finnish vehicle accident data and found no significant differences in road injury accidents amongst Fridays, once they had controlled for holidays. In addition, no increase in incidents has been found on Friday the 13th for post-tonsillectomy haemorrhage (Kumar et al., 2009), intraoperative blood loss (Schuld et al., 2011), relationship between a Friday the 13th birthdate and lifetime economic measures (Fidrmuc and Tena, 2014) and the number of hospital admission rates and emergency department visits (Lo et al., 2012).

The origin of many current lunar beliefs in a modern medical and public safety context can be traced to the Florida psychiatrist Arnold Lieber, in his 1978 book The Lunar Effect and his claim that homicides in Miami and Cleveland were tied to lunar patterns (Lieber and Agel, 1978; Lieber, 1996). He attributed this relationship to tidal forces within the human body called the "human tidal wave" or "biological tide" (Lieber and Sherin, 1972). It appears

that many of the well-accepted beliefs about full moons being busier or more unpredictable periods stem from this (Chakraborty and Ghosh, 2013). It is further strengthened by popular media, misconceptions of physics and cognitive biases (Rotton and Kelly, 1985a). In fact, it has been shown by Culver et al. (1988) that the gravitational force of the moon is $2 \mathrm{~m}$ times less than a $55 \mathrm{~kg}$ person standing a metre away. Furthermore, tidal effects are only possible in unbounded bodies of water (like the ocean) (Campbell, 1982).

Almost half of the general population believes the moon causes aberrant behaviour when it is full. Rotton and Kelly (1985a) found that 49.7 per cent of undergraduates at Florida University agreed that some people behave strangely when the moon is full. In a similar study about beliefs, Vance (1995) found that 43 per cent of general population holds the belief. Moreover, amongst mental health workers he found that the belief was as high as 81 per cent. Using the Belief in Lunar Effects scale developed by Rotton and Kelly (1985b), it was found that 64 per cent of emergency physicians, 74 per cent of psychiatric nurses and 80 per cent of emergency room nurses believe the moon affects patients.

Despite these common beliefs, no substantial evidence exists that either the full moon or Friday the 13th has any effect on human behaviour. Meta-analysis of 37 published and unpublished studies by Rotton and Kelly (1985a) looked at behaviours such as alcoholism, epilepsy, suicide, crisis centre calls, psychiatric admissions, birth rates, homicide and disasters. They concluded that no relationship exists between the phases of the moon and the studies' behaviours. In a later review by Kelly et al. (1996), the authors concluded that those papers that showed any relationship between moon phase and 
behaviour was due to inconsistent methodologies, confounding errors and overall reflected type I errors. Even if the positive results were accepted they only accounted for $3 / 100$ of 1 per cent of the variance in the various measures (Rotton and Kelly, 1985a). Several other extensive review articles have also described the lack of any lunar relationship (Abell, 1981; Cooke and Coles 1978; Campbell and Beets, 1978; Foster and Roenneberg, 2008; Raison et al., 1999; losif and Ballon, 2005). Foster and Roenneberg (2008) in their review paper cited 45 studies that found no consistent relationship between lunar influence and psychosis, depression, anxiety, violent behaviour, aggression, seizures, suicides, absenteeism rates, coronary failure, conception, birth, menstruation, surgery and survival of breast cancer, post-operative outcome, renal colic, outpatient admissions and automobile accidents. Schafer et al. (2010) cited several additional studies in which no lunar effect was found on prison escapes, hospital admissions for dog bites, hockey player aggression and homicide.

Margot (2015) showed that the few studies that found a relationship between the phase of the moon and the studied effect have typically made one of the following errors: small sample size, short period of study, lack of control for holidays or day of the week, cycle of the moon sampling procedure or statistical testing. Thus, our study aims to address these errors. Our hypothesis is that there is no difference in the number of incidents between regular days and superstitious days, i.e., Friday the 13th and full moon in our longitudinal data sets.

\section{Method}

The data used in the analysis were sourced from the agencies either by accessing publicly available data sets: London Fire Brigade (LFB), Mountain Rescue England \& Wales (MREW) and Royal National Lifeboat Institution (RNLI) and by kind donation from the host agency: Association of Lowland Search and Rescue (ALSAR) Teams and International Search \& Rescue Incident Database (ISRID2).

\section{Data descriptions}

The LFB data represent all fires in the period January 2009-October 2014 which was made available by the London Mayor's office and is freely available to download. The dates show all fires, or services carried out by London Fire crews, including arson, house fires, car and vehicle extractions and mutual aid services across the border into neighbouring counties during that period. The data are quite rich with the date and time, spatial location of the response, as well as attribute data concerning the station, engine and nature of the response. However, this research only used the dates from the records. In total, 669,838 date records were used in this work.

The ISRID2 database is the latest incarnation of the data set funded by the US Government, and curated by Koester, comprising reports from international SAR teams on their searches, location, types of missing person and other descriptive information. While this research only required the dates, the full data are typically used by search managers globally to plan searches for missing or lost people (Koester, 2008). The original version of the data set contained 55,000 records which have been submitted by SAR teams internationally, and this latest version (after spurious and badly formatted dates were removed) amounted to 53,689 date records, with dates ranging from 1980 to 2014.

The UK Lowland SAR (LSAR) data consist of records from the Dorset, Midshires, Hampshire and Surrey SAR teams. All these teams are official ALSAR teams and gave their data for the purposes of research into spatial patterns of LSAR in Southern England carried out by Kingston University London. The data range from January 2009 to February 2015. The dates of RNLI services are published in the Lifeboat 
Journal and more recently through social media by the institution centrally and by individual lifeboat stations. The data set analysis runs from January 1970 to December 2010 and contains 10,477 records. Finally, the MREW data were provided by the MREW through their information officer. It consists of 5,904 records, ranging from January 1995 to December 2013. The details of the input data sets can be seen in Table I.

\section{Analysis and results}

The data were analysed using SPSS software version 22 for the statistical testing and Microsoft Excel for data organisation and descriptive statistics. There was some variation in the data sets, as described in the Data Descriptions section, and the various descriptive statistics for each data set are presented in Table I and Figures 1 and 2.

\section{Descriptive statistics}

It can be seen that there is some difference in distribution and size of the data sets, as well as duration and reporting period. It should also be noted that only two of the data sets (RNLI and LFB) are absolutely required and rigorously collected by the agencies in question, while the other data sets were collected voluntarily, with no obligation or centrally organised body overseeing the collection. Thus, there is some likelihood of gaps or potentially incorrect reporting in those data sets.

The average number of responses rises on a full moon in all cases (except MREW where it falls slightly); however, these are very small rises - typically less than 0.01 per cent increase. All other superstitious days or periods show a decrease in average responses except LFB fire responses which rose slightly above average on Fridays.

In Figure 3, we can see the percentage of responses by moon phase, day of the week and month listed by an organisation. This is the percentage of all responses that fall on that day or in that phase, as opposed to the average number of responses on the day or phase. The full moon phase actually accounts for a smaller number of response dates in most organisations; however, as we can see the average number of responses on those dates remains roughly the same, except for the RNLI data.

Weekends have higher numbers of response in the RNLI, ISRID and MREW, with the LFB having a busy Friday and Saturday and a quiet Sunday, in this data set. In the LFB, MREW and ISRID data we see a broad increase in responses in the northern hemisphere summer months (possibly flattened in ISRID data as it includes southern hemisphere data) which broadly correlates with increased outdoor activity. The RNLI data show a much bolder seasonal shape, with the summer months accounting for a significant rise in responses required. ALSAR appears to demonstrate a bimodal distribution. 


\begin{tabular}{|c|c|c|c|c|c|c|}
\hline Data set & LFB & & MREW & RNLI & ISRID & ALSAR \\
\hline Location & Greater London, UK & England & and Wales & UK & International & England \\
\hline Nature & Fire and rescue & Mountain se & search and rescue & Water rescue & Search and rescue & Search and rescue \\
\hline Date from & 1 January 2009 & 1 January 19 & 1995 & 1 January 1970 & 1 May 1980 & 8 January 2009 \\
\hline Date to & 31 October 2014 & 4 December & er 2013 & 26 February 2010 & 16 August 2014 & 1 February 2015 \\
\hline Length of period (days) & 2,129 & & 6,912 & 14,666 & 12,525 & 2,215 \\
\hline Number of records & $6,69,836$ & & 5,904 & 14,440 & 53,689 & 453 \\
\hline Max incidents per day & 840 & & 23 & 127 & 49 & 3 \\
\hline Average incidents per day & $314.48 \pm 56.8$ & $3.54 \pm 2.52$ & & $14.57 \pm 13.53$ & $6.39 \pm 6.94$ & $1.15 \pm 0.40$ \\
\hline Average incidents on full moons & $317.21 \pm 46.72$ & $3.24 \pm 2.21$ & & $15.14 \pm 14.28$ & $6.54 \pm 6.87$ & $1.33 \pm 0.65$ \\
\hline Average incidents on non-full moon days & $314.38 \pm 56.6$ & $3.55 \pm 2.57$ & & $14.54 \pm 13.92$ & $6.38 \pm 6.94$ & $1.15 \pm 0.4$ \\
\hline Average incidents during full moon period & $311.05 \pm 60.59$ & $3.41 \pm 2.60$ & & $15.48 \pm 14.63$ & $6.41 \pm 7.14$ & $1.22 \pm 0.65$ \\
\hline Average incidents on Friday 13th & $313.33 \pm 55.27$ & $2.46 \pm 0.70$ & & $10.49 \pm 10.27$ & $6.14 \pm 6.93$ & $1.00 \pm 0.00$ \\
\hline Average incidents on all Fridays & $317.90 \pm 56.80$ & $3.05 \pm 2.29$ & & $11.65 \pm 10.19$ & $7.80 \pm 7.02$ & $1.10 \pm 0.48$ \\
\hline Average incidents on all 13ths & $308.9 \pm 48.49$ & $1.58 \pm 2.43$ & & $11.12 \pm 14.63$ & $6.14 \pm 6.94$ & $1.15 \pm 0.43$ \\
\hline
\end{tabular}

Notes: LFB, London Fire Brigade; MREW, Mountain Rescue England and Wales; RNLI, Royal National Lifeboat Institution; ISRID, International Search \& Rescue Incident Database 

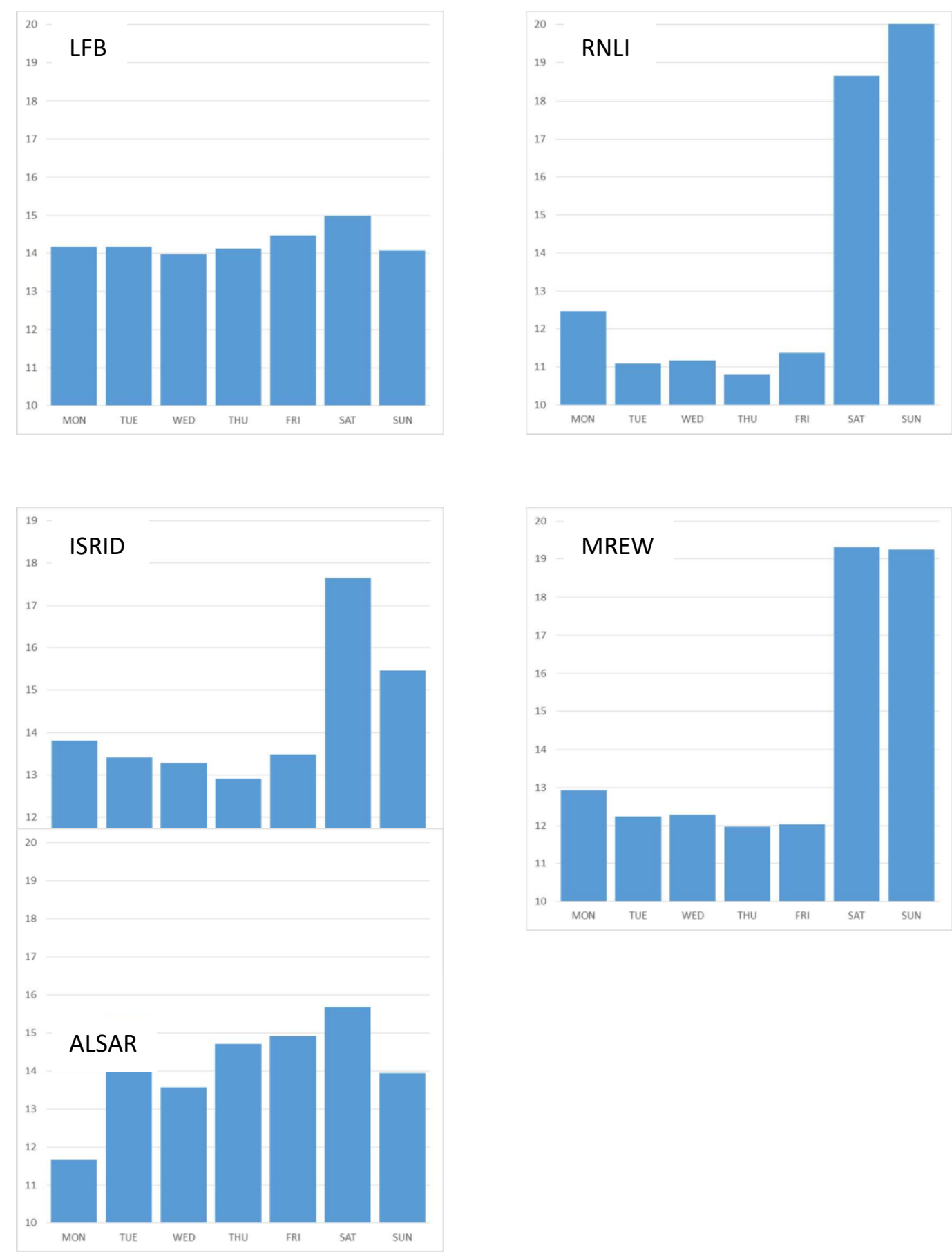

Figure 1. Percentages of responses per day of the week 

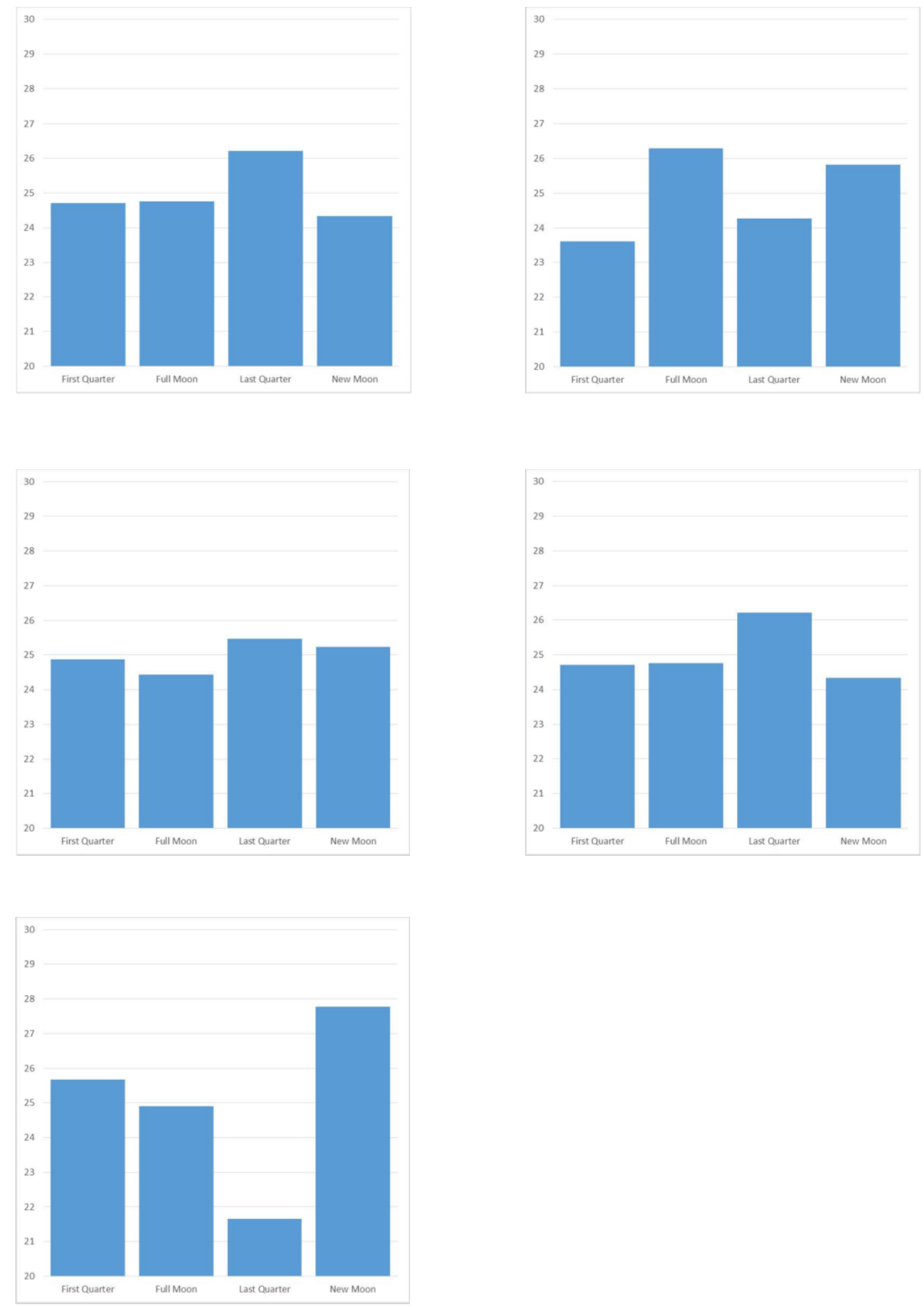

Figure 2. Percentages of responses per month 

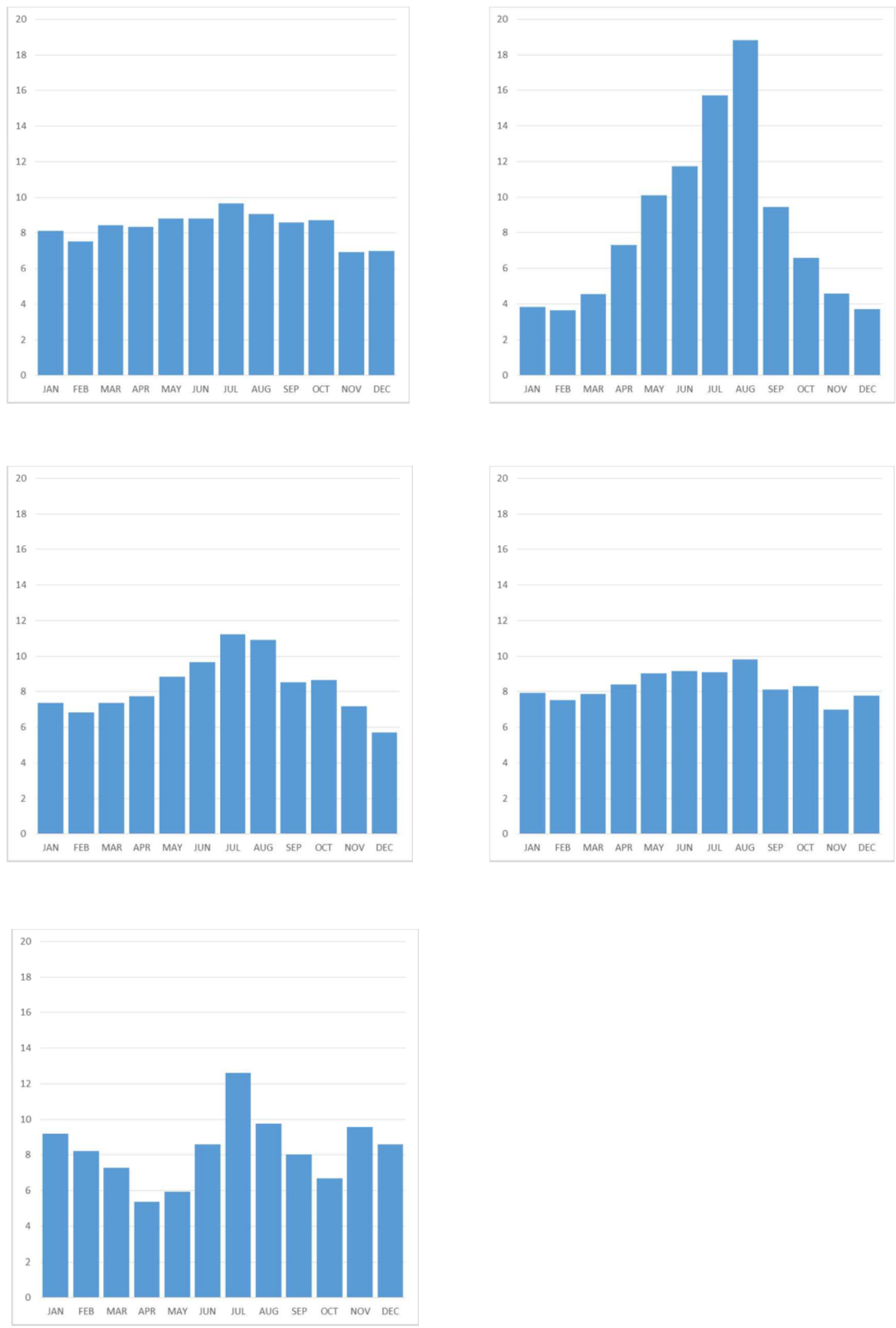

Figure 3. Percentages of responses in each phase of the moon 
To investigate if significant differences existed between the number of responses on full moons vs normal days, or Friday 13th vs normal Fridays or all other days, separate Mann-Whitney U-tests were carried out on the five data sets, as illustrated in Table II. The cells highlighted in green represent the only pairwise comparisons that showed a significant level of difference between the ranked means of the pairs.

\section{Discussion}

An examination of five different public safety databases fails to support the superstition or

myth that Friday the 13th or full moons results in an increase in the number of incidents.

The lack of any correlation between the superstitions and fire incidents, maritime rescue incidents and land SAR can be added to a long list of previous studies that found no significant increase as described in the Literature Review section. This is the first paper to examine any possible relationship between full moons and Friday the 13th in an SAR context. The study did find clear relationships showing an increase in incidents based upon the day of the week and month of the year.

Why is this paper even necessary? No scientific mechanism suggests why the combination of two manmade calendar events of Friday and the 13th would have an effect. Yet the belief remains strong with as many as 70 per cent of the population in some places believing in the relationship (KrajewskaKulak et al., 2011). Individuals who work in public safety or emergency medicine are particularly likely to be even more superstitious than the general public (Vance, 1995; Rotton and Kelly, 1985b). A hallmark of public safety and SAR is the general unpredictability of when incidents will occur. Humans in general prefer to see patterns to help explain unpredictability. This provides a sense of control and reduces anxiety according to Vance (1995). Therefore, it should not be too surprising that professions exposed to some of the highest levels of unpredictability express some of the highest levels of superstitious beliefs.

A similar belief exists that full moons will result in increased incidents. This hypothesis was not supported by the results of our study for any of the five data sources. However, at least a

\begin{tabular}{|l|l|l|l|l|}
\hline & $\begin{array}{c}\text { Full Moon v not } \\
\text { Full Moon }\end{array}$ & \multicolumn{1}{|c|}{ 13th v F13 } & \multicolumn{1}{|c|}{ Fridays v F13s } & All days v F13s \\
\hline LFB & $\mathrm{U}=73136.5 \mathrm{p}=0.853$ & $\mathrm{U}=275.5 \mathrm{p}=0.429$ & $\begin{array}{l}\mathrm{U}=1558.500 \\
\mathrm{p}=0.839\end{array}$ & $\mathrm{U}=10603.0000 .605$ \\
\hline RNLI & $\mathrm{U}=3291215.0$ & $\mathrm{U}=12314.500 \mathrm{p}=0.138$ & $\begin{array}{l}\mathrm{U}=67381.000 \\
\mathrm{p}=0.999\end{array}$ & $\begin{array}{l}\mathrm{U}=435837.500 \\
\mathrm{p}=0.123\end{array}$ \\
\hline MREW & $\mathrm{U}=0.34$ & $\mathrm{p}=0.215$ & $\begin{array}{l}\mathrm{U}=5633.500 \\
\mathrm{p}=0.000\end{array}$ & $\mathrm{U}=34942.500 \mathrm{p}=0.000$ \\
\hline ISRID & $\mathrm{U}=1103257.0 \mathrm{p}=0.7$ & $\begin{array}{l}\mathrm{U}=4057.500 \\
\mathrm{p}=0.463\end{array}$ & $\begin{array}{l}\mathrm{U}=20288.000 \\
\mathrm{p}=0.744\end{array}$ & $\begin{array}{l}\mathrm{U}=146060.500 \\
\mathrm{p}=0.547\end{array}$ \\
\hline ALSAR & $\mathrm{U}=2309.5 \mathrm{p}=0.212$ & $\begin{array}{l}\mathrm{U}=10.500 \\
\mathrm{p}=0.299\end{array}$ & $\mathrm{U}=66.000 \mathrm{p}=0.321$ & $\mathrm{U}=582.000 \mathrm{p}=0.493$ \\
\hline
\end{tabular}

Table II. Results of the Mann-Whitney U-tests, with statistically significant results highlighted in green 
electrical lights, this factor no longer exists (Raison et al., 1999). Therefore, it is not surprising that numerous scientific papers have found no effect of a full moon in human behaviour.

This study did find that for Friday the 13th, a statistically significant decrease in incidents did occur in the MREW data (compared to the 13th, Fridays and all other days of the month). Five possible explanations exist: the decrease is based upon chance; some unrecognised confounding factor exists; a recording bias exists; Friday the 13th has a supernatural ability to decrease incidents; or risk compensation exists. The MREW decrease was statistically significance ( $p 0.000)$ with a MannWhitney U-test, there may still be the result of chance. It might be argued that the test should be adjusted to reflect that a relationship amongst 20 different comparisons should have been performed. The MREW database had a relatively low number of responses on average for Friday the 13th (2.46) and for any Friday as well (3.05). While this represents a 19.3 per cent decrease for a Friday the 13th, it only represents half an incident per day. Any change at all in signal response figures per day would result in a statistically significant effect in this case, since the average responses are so low. So, between a low overall incident rate, a smaller data collection period and the sampling of 20 parameters it should not be too surprising that a significant decrease was seen. From an SAR operational perspective, this decrease has no practical implications. This effect drops out amongst the other four databases with larger average incident counts. One potential confounding factor this study did not examine is how many of the Fridays were holidays vs the number of Friday the 13th that were holidays. This study clearly showed an increase in incidents occurring on Saturday and Sunday. Therefore, it would be expected that any holiday on Friday would have a higher number of incidents. It is possible that a reporting bias might exist in the MREW database since it is not a mandatory database. However, while reporting a specific behaviour is often open to some speculation, an incident is largely objective and not open to much interpretation. Clearly the intrinsic unlucky supernatural nature of Friday the 13th did not result in more SAR incidents. However, risk compensation may offer a good explanation for the decrease in incidents on Friday the 13th. Risk compensation on Friday the 13th has been hypothesised for the decrease in traffic accidents in Finland (Radun and Summala, 2004) and decrease in emergency room visits (Lo et al., 2012). Radun and Summala offered the explanation that those who are anxious about Friday the 13th choose safer options and avoid risk. Similar risk compensation is observed with a decrease in drowning observed in Southern China during the "unlucky" Ghost Month (lunar June) reported by Yang et al. (2008). A 10 per cent decrease in incidents on Friday the 13th (but still statistically insignificant) was also seen in the RNLI data. Sailors are regarded as a generally superstitious group and may also risk compensate (Vyse, 2014).

Amongst the quarter of the moon data, no significant effect is seen amongst any of the five databases. The database that appears to have the most variation is the RNLI data, which show an 8.9 per cent increase in incidents during full and new moons phase compared to the two quarters. In this case, the full and new moon phases correspond to the largest tidal differences. It is hypothesised that greater differences in tides and tidal currents may account for the increased number.

All the data sets, except for the ALSAR data show a strong increase in the number of incidents that occur on weekends. This can largely be accounted for by increased recreational activity on weekends. This trend was observed in the first known collection of SAR data from Kelley (1973). The lack of a strong weekend trend in the ALSAR data may be due to the large number of dementia and despondent cases found in the data. Many dementia subjects are not aware of the day of the week or constrained by weekly schedules. Suicide occurrence has been shown to peak on Mondays with a slight dip in occurrence on the weekend by Maldonado and Kraus (1991). The general trend in western countries is that suicides are the least frequent on weekends and most frequent on Mondays and Tuesdays (Ajdacic-Gross et al., 2014). All the databases show a seasonal variation with the peak during the 
summer months. Once again this would correlate to increased recreational activity. The RNLI data showed the greatest effect. The ISRID data are somewhat muted due to the inclusion of data from both the northern and southern hemisphere. ALSAR appears to demonstrate a bimodal distribution with peaks in the summer (i.e. increased activity) and around Christmas and the New Year.

\section{Limitations}

Any data-based investigation is at the mercy of the data available and this is the case in this work. Although the same criteria have been applied across data sets, and this does not change the core findings, there are inconsistencies between the sources. Specifically, the date range, average frequency, reporting methodology and population size of the component data sets are not standard. This does not pose too much of a barrier in this research but could pose problems for further work.

Furthermore, this work has only considered the frequencies and percentages of responses during the periods in question, and although we offer some potential explanations for phenomena, these have not been examined in any detail. Further work is required to attempt to determine why response rates rise or drop during reporting periods.

\section{Future research}

Despite this research indicating that no demonstrable differences appear between the superstitious dates and normal days (and this is entirely consistent with previous work, especially as in this case with previously untested or unavailable data), it is still of use and interest to test for seasonal fluctuations in rescue or emergency response data. If any possibility exists for understandable and predictable surges in response requirements, then all efforts should be made to determine and understand them. On the other hand, dispelling myths both within and outside the rescue community serves a useful purpose. To that end, rigorous quantitative analysis of response data should be carried out with similar data sets, or in the future to determine if any changes have occurred.

Furthermore, this research has only considered patterns in time, and compared average response numbers across certain timeframes. Further research could look more closely at the spatiotemporal aspects of this phenomenon; perhaps investigating whether proximity to major watercourse or coastline has any impact on rescue responses during a full moon. There could also be some investigation into any identifiable cultural/spatial patterns concerning superstition and response, such as areas in which there is such a strong belief in a superstition that it actually affects a society's behaviour, such as in the case of Ghost Month (Yang et al., 2008).

\section{Conclusion}

Most scientists would probably not be surprised by the general results of this work; there is no statistically significant change in human behaviour detected, nor any change in response patterns across the organisations studied in the periods observed. There are some small statistical anomalies which can largely be explained by the nature of the input data, but certainly do not provide any dramatic new confirmation of the myths.

The real value of this work lies in the practical application of the null hypothesis. Krajewska-Kulak et al. (2011) showed that the beliefs are still well-established, and this set of beliefs is likely to be 
represented within the SAR or Fire communities. Indeed, this is supported by reports such as BBC (2007). Thomas (1982) well described the decline of magic and religion (often associated with superstitions) starting in the sixteenth century. Nevertheless, the outcome of recent experiments with adults led Subbotsky (2004, p. 149) to conclude that "magical beliefs persist in the modern industrialized world but are disquised to fit the dominant scientific paradigm". However, search or fire operations are often fundamentally about resource management. Potentially, hours of searching, or money and resources could be wasted

by inefficient deployment or a deployment based on an incorrect assumption.

Although it might be regarded by the scientific community that this is established through logic and rational thought, that does not necessarily mean that the practitioner community responds as such or is even aware of that position. This is reminiscent of the dissemination of climate change science, where simply informing the public of the scientific position does not in itself result in changes of behaviour or attitude. The practical testing of real-world data, aligned to a number of practicing and tangible rescue services, we hope, allows the message to be more widely and more natively disseminated to those practitioners in the field who are responsible for resource management.

\section{Glossary}

$\begin{array}{ll}\text { ALSAR } & \text { Association of Lowland Search and Rescue } \\ \text { F13 } & \text { Friday 13th dates } \\ \text { ISRID } & \text { International Search \& Rescue Incident } \\ \text { Database LFB } & \text { London Fire Brigade } \\ \text { LSAR } & \text { Lowland Search \& Rescue } \\ \text { MREW } & \text { Mountain Rescue England and Wales } \\ \text { RNLI } & \text { Royal National Lifeboat Institution } \\ \text { SAR } & \text { Search and Rescue } \\ \text { UK } & \text { United Kingdom } \\ \text { US } & \text { United States }\end{array}$




\section{References}

Ajdacic-Gross, V., Tran, U., Bopp, M., Sonneck, G., Niederkrotenthaler, T., Kapusta, N., Rössler, W., Seifritz,

E. and Voracek, M. (2014), "Understanding weekly cycles in suicide: an analysis of Austrian and Swiss data over 40 years", Epidemiology and Psychiatric Sciences, Vol. 24 No. 4, pp. 315-321.

BBC (2007), "Crackdown on lunar-fueled crime", available at: http://news.bbc.co.uk/1/hi/england/kent/ 6723911.stm (accessed 1 January 2016).

Bickis, M., Kelly, I.W. and Byrnes, G.F. (1995), "Crisis calls and temporal and lunar variables: a comprehensive examination", Journal of Psychology, Vol. 129 No. 6, pp. 701-711.

Campbell, D.E. (1982), "Lunar-lunacy research: when enough is enough", Environment and Behavior, Vol. 14 No. 4, pp. 418-424.

Campbell, D.E. and Beets, J.L. (1978), "Lunacy and the moon", Psychological Bulletin, Vol. 85 No. 5, pp. 1123-1129.

Chakraborty, U. and Ghosh, T. (2013), "A study on the physical fitness index, heart rate and blood pressure in different phases of lunar month on male human subjects", International Journal of Biometeorology, Vol. 57 No. 3, pp. 769-774.

Cooke, D.J. and Coles, E.M. (1978), "The concept of lunacy: a review", Psychological Reports, Vol. 42 No. 3, pp. 891-897.

Culver, R., Rotton, J. and Kelly, I.W. (1988), "Moon mechanisms and myths: a critical appraisal of explanations of purported lunar effects on human behaviour", Psychological Reports, Vol. 62, pp. 683710.

Fidrmuc, J. and Tena, J.D. (2014), "Friday the 13th: the empirics of bad luck (October 23, 2014)", CESifo Working Paper Series No. 5,026, available at: http://ssrn.com/abstract=2518923

Foster, R.G. and Roenneberg, T. (2008), "Human responses to the geophysical daily, annual and lunar cycles”, Current Biology, Vol. 18 No. 17, pp. R784-R794.

Frey, J., Rotton, J. and Barry, T. (1979), "The effects of the full moon on human behavior: yet another failure to replicate", The Journal of Psychology: Interdisciplinary and Applied, Vol. 103 No. 2, pp. 159162.

Gooch, S. (2006), The Dream Culture of the Neanderthals: Guardians of the Ancient Wisdom, Inner Traditions/Bear, Rochester, VT.

losif, A. and Ballon, B. (2005), "Bad moon rising: the persistent belief in lunar connections to madness", Canadian Medical Association Journal, Vol. 173 No. 12, pp. 1498-1500. Kelley, D. (1973), Mountain Search for the Lost Victim, Kelley, Montrose, CO.

Kelly, I., Rotton, J. and Culver, R. (1996), "The moon was full and nothing happened: a review of studies on the moon and human behaviour and human belief", in Nickell, J., Karr, B. and Genoni, T. (Eds), The Outer Edge: Classic Investigations of the Paranormal, CSICOP, Amherst, NY, pp. 17-34.

Koester, R. (2008), Lost Person Behavior: A Search and Rescue Guide on Where to Look - for Land, Air and Water, dbS Productions, Charlottesville, VA. 
Krajewska-Kulak, E., Kulak, W., Radziejewski, P., Rozwadowska, E., Lankau, A., Kowalewska, B., Kondzior, D., Szyzko-Perlowska, A., Krajewska-Perishah, K., Ortman, E. and Moczydlowska, A. (2011), "Current view of the traditional superstitions in general population of Podlaskie province: preliminary study", Progress in Health Sciences, Vol. 1 No. 2, pp. 76-83.

Kumar, V., Kumar, N. and Isaacson, G. (2004), "Superstition and post-tonsillectomy hemorrhage", The Laryngoscope, Vol. 114 No. 11, pp. 2031-2033.

Lieber, A.L. (1996), How the Moon Affects you, Hastings House, Mamaroneck, NY. Lieber, A.L. and Agel, J. (1978), The Lunar Effect: Biological Tides and Human Emotions, Anchor Press,

Garden City, NY.

Lieber, A. and Sherin, C. (1972), "Homicides and the Lunar Cycle: toward a theory of Lunar influence on human emotional disturbance", American Journal of Psychiatry, Vol. 129 No. 1, pp. 69-74.

Lo, B.M., Visintainer, C.M., Best, H.A. and Beydoun, H.A. (2012), "Answering the myth: use of emergency services on Friday the 13th", American Journal of Emergency Medicine, Vol. 30 No. 6, pp. 886-889.

Lorie, P. (1992), Superstitions, Simon \& Schuster, New York, NY.

Maldonado, G. and Kraus, J.F. (1991), "Variation in suicide occurrence by time of day, day of the week, month, and lunar phase", Suicide and Life-Threatening Behavior, Vol. 21 No. 2, pp. 174-187.

Margot, J. (2015), "No evidence of purported lunar effect on hospital admission rates or birth rates",

Nursing Research, Vol. 64 No. 3, pp. 168-176.

Nayha, S. (2002), "Traffic deaths and superstition on Friday the 13th", The American Journal of Psychiatry, Vol. 159 No. 12, pp. 2110-2111.

Packer, C., Swanson, A., Ikanda, D. and Kushnir, H. (2011), "Fear of darkness, the full moon and the nocturnal ecology of African lions", PLoS One, Vol. 6, No. 7, p. e22285.

Radun, I. and Summala, H. (2004), "Females do not have more injury road accidents on Friday the 13th", BMC Public Health, Vol. 4 No. 1, pp. 1-4.

Raison, C.L., Klein, H.M. and Steckler, M. (1999), "The moon and madness reconsidered", Journal of Affective Disorders, Vol. 53 No. 1, pp. 99-106.

Rotton, J. and Kelly, I. (1985a), "Much ado about the full moon: a meta-analysis of lunar-lunacy research", Psychological Bulletin, Vol. 97 No. 2, pp. 286-306.

Rotton, J. and Kelly, I. (1985b), "A scale for assessing belief in lunar effects: reliability and concurrent validity", Psychological Reports, Vol. 57 No. 1, pp. 239-245.

Scanlon, T.J., Luben, R.N., Scanion, F.L. and Singleton, N. (1993), "Is Friday the 13th bad for your health", British Medical Journal, Vol. 307 No. 6919, pp. 1584-1586.

Schafer, J.A., Varano, S.P., Jarvis, J.P. and Cancino, J.M. (2010), "Bad moon on the rise? Lunar cycles and incidents of crime", Journal of Criminal Justice, Vol. 38 No. 4, pp. 359-367.

Schuld, J., Slotta, J.E., Schuld, S., Kollmar, O. and Schilling, M.K. (2011), "Popular belief meets surgical reality: impact of lunar phases, Friday the 13th and Zodiac signs on emergency operations and intraoperative blood loss", World Journal of Surgery, Vol. 35 No. 9, pp. 1945-1949. 
Sivak, M., Schoettle, B. and Tsimhoni, O. (2007), "Moon phases and night time road crashes involving pedestrians", LEUKOS, Vol. 4 No. 2, pp. 129-131.

Subbotsky, E. (2004), "Magical thinking in judgments of causation: can anomalous phenomena affect ontological causal beliefs in children and adults?", British Journal of Developmental Psychology, Vol. 22 No. 1, pp. 123-152.

Thomas, K. (1982), Religion and the Decline of Magic: Studies in Popular Beliefs in Sixteenth and Seventeenth-Century England, Penguin, London.

Vance, D. (1995), "Belief in lunar effects on human behaviour", Psychological Reports, Vol. 76 No. 1, pp. 32-34.

Vyse, S. (2014), Believing in Magic: The Psychology of Superstition, Oxford University Press, Oxford.

Yang, C.H., Huang, Y.T., Janes, C., Lin, K.C. and Lu, T.H. (2008), "Belief in ghost month can help prevent drowning deaths: a natural experiment on the effects of cultural beliefs on risky behaviours", Social Science \& Medicine, Vol. 66 No. 9, pp. 1990-1998.

\section{Further reading}

Abell, G.O. (1979), "Review of the 'the lunar effect' by Arnold Lieber", Skeptical Inquirer, Vol. 3 No. 3, pp. 68-73.

Kelly, I.W., Rotton, J. and Culver, R. (1986), "The moon was full and nothing happened", Skeptical Inquirer, Vol. 10 No. 2.

Smith, S. (2015), "The aggressive behaviour of individuals with intellectual disabilities is not affected by a full moon: a 17-year study", Comprehensive Psychology, Vol. 4 No. 5, pp. 1-6. 